\title{
Sleep-disordered breathing and daytime postural stability
}

\author{
Francis Degache, ${ }^{1,2}$ Yannick Goy, ${ }^{3}$ Sopharat Vat, ${ }^{4,5}$ José Haba Rubio, ${ }^{4}$ Olivier Contal, ${ }^{1}$ \\ Raphaël Heinzer ${ }^{4}$
}

${ }^{1}$ Department of Health

Research, University of Health Sciences, University of Applied Sciences and Arts Western Switzerland, Lausanne, Switzerland

${ }^{2}$ Department of Physiology, GRISSUL (Group of Research of Institute of Sports Sciences), University of Lausanne, Lausanne, Switzerland ${ }^{3}$ Department of Physiology, Faculty of Biology and Medicine, Institute of Sports Sciences, University of Lausanne, Lausanne, Switzerland

${ }^{4}$ Center for Investigation and Research in Sleep (CIRS) University Hospital of Lausanne (CHUV), Lausanne, Switzerland ${ }^{5}$ Pulmonary Medicine Department, University Hospital of Montreal (CHUM), Montreal, Canada

\section{Correspondence to}

Francis Degache, University of Health Sciences, University of Applied Sciences and Arts Western Switzerland, Av Beaumont 21, Lausanne 1011, Switzerland francis.degache@hesav.ch

This study has been previously reported in abstract form at the the 22nd Congress of the European Sleep Research Society, 16-20 Sept 2014 Tallinn, Estonia.

Received 26 June 2015 Revised 3 January 2016 Accepted 22 January 2016 Published Online First 18 February 2016

\section{CrossMark}

To cite: Degache F, Goy Y, Vat $\mathrm{S}$, et al. Thorax 2016:71:543-548.

\section{ABSTRACT \\ Objective Postural stability depends on the} coordination of the central nervous system with visual sense, proprioceptive and vestibular information. Sleep deprivation has been shown to affect this function. The objective of our study was to assess the effects of sleepdisordered breathing (SDB) on postural stability.

Methods 158 subjects referred for suspected SDB had an overnight sleep study and were placed on a posturographic platform in late afternoon. This platform allows measuring the centre of pressure $(C O P)$ oscillations and to calculate: total displacement of $\mathrm{COP}$ in $X$ and $Y$ axes, mean speed of $C O P$ displacement and the length as function of surface (LFS) ratio (length of COP displacement/surface of COP trajectory).

Results 98 men and 60 women were included. Mean age \pm SD was $45.4 \pm 5.5$ years old, body mass index (BMI) $27.5 \pm 5.6 \mathrm{~kg} / \mathrm{m}^{2}$ and apnoea-hypopnoea index (AHI) $13.6 \pm 16.1 / \mathrm{h}$. AHI was $<5 / \mathrm{h}$ in $64(41 \%)$ subjects, $5-15 / \mathrm{h}$ in $43(27 \%), 15-30 / \mathrm{h}$ in $30(19 \%)$ and $>30 / \mathrm{h}$ in $21(13 \%)$. In patients with an $\mathrm{AHI}>5 / \mathrm{h}$ versus $\mathrm{AHI}$ $<5 / h$, we observed an important increase in LFS $(+21 \%$, $p<0.001)$, in $X Y$ length $(+23 \%, p<0.001)$ and in mean speed $(+23 \%, p<0.001)$. After controlling for age, BMI and sleepiness (Epworth) in multivariate regression models, there was a positive association between all nocturnal breathing parameters (specifically: mean $\mathrm{SpO}_{2}$, $\mathrm{AHI}$, oxygen desaturation index $3 \%$ and $\%$ time with $\mathrm{SpO}_{2}<90 \%$ ) and the main stability outcomes (all $\mathrm{p}<0.05)$.

Conclusions SDB severity, especially the mean nocturnal $\mathrm{SpO}_{2}$ level, is associated with impaired daytime postural stability.

\section{INTRODUCTION}

Sleep-disordered breathing (SDB) is a disabling condition caused by repeated episodes of upper airway obstruction during sleep, resulting in nocturnal hypoxaemia and fragmented sleep. ${ }^{1}$ Moreover, this condition is associated with an increased risk of hypertension, stroke, heart failure, diabetes, car accidents and depression. ${ }^{2-10}$ SDB has also been shown to alter reaction time and reflexes while driving with an improvement after SDB treatment. $^{11}$

Postural stability is an important function of the human body. ${ }^{12}$ The body postural control depends on the coordination of the central nervous system with visual sense, proprioceptive and vestibular information to control the effector organs (skeletal muscles of the legs, gait and trunk). Any alteration in these integrative processes will negatively

\section{Key messages}

What is the key question?

- Is sleep-disordered breathing associated with impaired postural stability?

What is the bottom line?

- There is an independent association between nocturnal breathing disorders parameters, especially the apnoea-hypopnoea index and nocturnal oxygen level and impaired postural stability.

\section{Why read on?}

- This study analyses the determinants of postural instability in patients with sleep-disordered breathing and the possible pathophysiological mechanisms, which may be responsible for this association.

influence postural control. ${ }^{13}$ In a healthy individual, central nervous system uses small-amplitude postural oscillations to keep the body close to vertical alignment. ${ }^{14}$ The bipedal control of posture has primarily been studied by analysing the trajectory of the centre of pressure $(\mathrm{CoP})$, which can be easily recorded using posturographic platforms. ${ }^{15}$

It has been shown that balance and gait impairments in older people increase the risk of falls, which is the leading cause of accidental death and injury-related visits to emergency departments. ${ }^{16}$ Postural control is the foundation of our ability to stand and to walk independently. Deterioration of postural stability in patients with SDB may contribute to falls occurring during activities of daily life, in particular among older patients.

It has also been shown that postural stability is affected by $>19,24$ or 48 h sleep deprivation. ${ }^{17-20}$ The negative effects of sleep deprivation on postural sway seem to be due to the reduced levels of alertness $^{19}$ and peaks when the body temperature reaches its minimum. ${ }^{20}$ After a night of sleep deprivation, the bilateral posterior-parietal and prefrontal areas are less activated, ${ }^{21} 22$ thereby prompting an alteration in sensorimotor integration.

Another factor that can affect postural stability is hypoxia. Recently, Degache et $a l^{23}$ showed that short exposure to hypobaric hypoxia at an altitude of 1700 and $3000 \mathrm{~m}$ could deteriorate the postural 


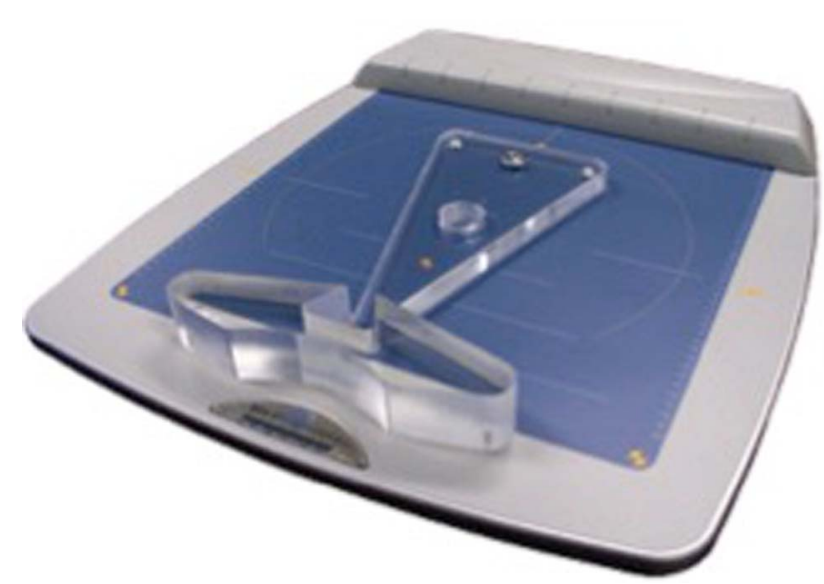

Figure 1 Posturographic platform (Fusyo-Medicapteur, Toulouse, France; Dekra certification).

control. Moreover, in normobaric hypoxia condition, significant disturbances of postural stability were observed when blood oxygen saturation level $\left(\mathrm{SpO}_{2}\right)$ decreased to $70 \%$ during $10 \mathrm{~min}$ by breathing hypoxic gas $\left(\mathrm{FIO}_{2}: 6 \%-10 \%\right) .^{24}$

Considering the decreased sleep quality and repeated oxygen saturation drops observed in SDB, we sought to test the hypothesis that daytime postural control could be impaired in patients with SDB compared with control subjects.

\section{MATERIAL AND METHOD \\ Population}

Subjects were recruited among consecutive patients referred to the Lausanne University Sleep Centre for suspected SDB and were informed about the protocol by post mail prior to the sleep study. Inclusion criteria were age $\geq 18$ years and ability to give an informed consent. Exclusion criteria were the presence of a neurodegenerative disease, peripheral neuropathy, pregnancy (shift of the gravity centre), spinal or lower limb disease, inner ear disease affecting stability, any medication affecting the central nervous system and chronic alcohol consumption. Those who fulfilled these criteria were included in the study and had a stabilometry testing in the late afternoon before the sleep study.

This study was approved by the Cantonal Ethics Committee of Lausanne, Switzerland (\# 474/12). All subjects provided written, voluntary, informed consent prior to participation. The experiment was conducted according to the Declaration of Helsinki.

\section{Postural stability protocol}

A posturographic platform (Fusyo-Medicapteur, Toulouse, France; Dekra certification) with a sampling rate of $40 \mathrm{~Hz}$ was used for postural stability assessment (figure 1). CoP excursion data were recorded using a PC computer with Fusyo software V.1.2.1. The posturographic platform measured $530 \mathrm{~mm} \times 460$ $\mathrm{mm} \times 35 \mathrm{~mm}$ and was equipped with three pressure gauges (hysteresis $<0.2 \%$ ). Signal processing was accomplished using a 16-bit A/D converter at $40 \mathrm{~Hz}^{25}$ The duration of each test was $51.2 \mathrm{~s}$, resulting in a 2048-point time series.

The subjects were placed on the posturographic platform (figure 1) using precise markers (figure 2). Their legs were extended, and their feet formed a $30^{\circ}$ angle relative to each other with an intermalleolar distance of $5 \mathrm{~cm}$. The subjects were instructed to maintain their balance, while looking at a fixed target at a distance of $90 \mathrm{~cm}$ with their arms at their sides and to look straight ahead. The height of the visual target was adjusted for each subject. The verbal instructions were as follows: 'Stand with your arms at your sides and look straight ahead while trying to maintain your postural stability to your best ability'. The aim of these instructions was to limit their sway as much as possible.

\section{Data acquisition and analyses}

CoP oscillations were collected and allowed calculating the standard postural sway parameters: (1) total displacement of $\mathrm{CoP}$ in anteroposterior ( $\mathrm{Y}$ axis) and mediolateral (X axis) plan (length in $\mathrm{mm})$; (2) mean speed of CoP displacement $(\mathrm{mm} / \mathrm{s})$ and (3) LFS ratio corresponding to the length of the CoP displacement as a function of the surface of CoP trajectory (index of energy expenditure). ${ }^{26}$
A

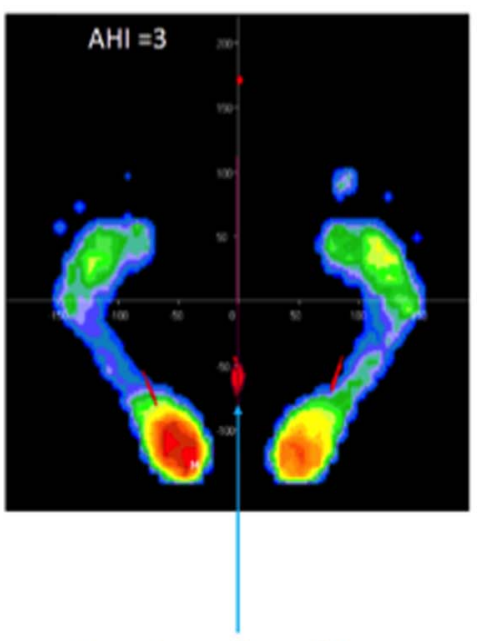

Normal «small» oscillations

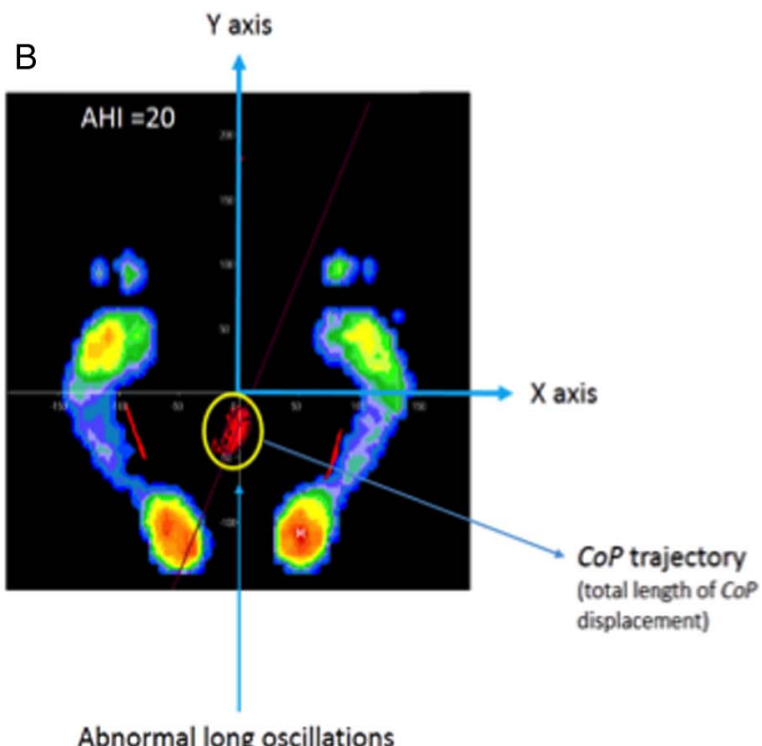

Abnormal long oscillations

Figure 2 Positioning of feet on posturographic platform during postural control analysis in (A) a subject with no sleep-disordered breathing (SDB) (apnoea-hypopnoea index $(A H I)=3 / h)$ and in $(B)$ a patient with SDB $(A H I=20 / h)$. COP, centre of pressure. 


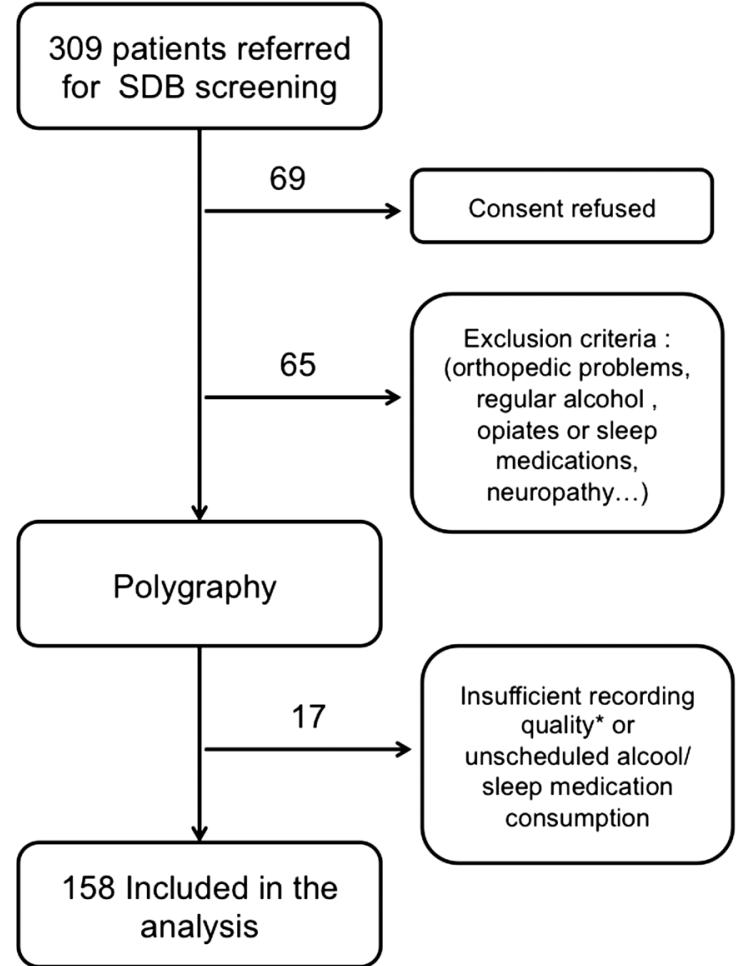

${ }^{\star}$ Reported total sleep time $<4$ hours, $N=8$; Technical problem, $n=9$.

Figure 3 Patients flow chart. SDB, sleep-disordered breathing.

\section{Sleep recordings}

Subjects were equipped with a type 3 ambulatory limited channel recorder Embletta system (Embla Systems, Broomfield, Colorado, USA) at the sleep lab in the afternoon by a trained sleep technician. This device records nasal air pressure, thoracic and abdominal movements, oxygen saturation $\left(\mathrm{SpO}_{2}\right)$ level, heart rate and body position. The subjects slept at home and brought the recorder back to our sleep lab the next morning.

All sleep recordings were manually scored by a trained physician (SV) using Somnologica software V.5.1.1 (Embla Flaga, Reykjavik, Iceland) and reviewed by a second physician ( $\mathrm{RH}$ or
JHR). Apnoea was defined as a $90 \%$ of airflow drop from baseline lasting $10 \mathrm{~s}$ or longer. Hypopnoea was defined as a $\geq 30 \%$ drop of airflow signal lasting at least 10 s or longer with a $\geq 3 \%$ oxygen desaturation. The average number of apnoea and hypopnoea per hour (apnoea-hypopnoea index (AHI)) was calculated. AHI was divided into the standard categories (normal $<5 / \mathrm{h}$, mild SDB 5-15/h, moderate SDB 15.1-30/h and severe SDB $>30 / \mathrm{h}$ ). The oxygen desaturation index (ODI) corresponding to the number of $3 \%$ oxygen drops per hour as well as the mean oxygen saturation level and \% of the night with an oxygen saturation below 90\% were also calculated. Daytime sleepiness was assessed using the Epworth Sleepiness Scale (ESS). ${ }^{27}$ A score $>10 / 24$ was considered abnormal.

\section{Statistical analyses}

All data presented in the text, tables and figures are the mean value $\pm S D$ unless otherwise specified. Comparisons between subjects with and without SDB were performed with Student's t tests or Mann-Whitney tests when the data were not normally distributed. Correlations were performed using Spearman tests. Linear regression models were used to estimate the association between SDB parameters and postural stability with sleep variables used as independent variables and postural variables as dependent variables. The $\mathrm{N}$ for this analysis was 138 due to missing Epworth scores. A Fisher's exact test was used to compare proportional data between groups. The significance level was set at $\mathrm{p}<0.05$. Statistical analysis was performed using biomedical software MedCalc for Windows V.11.4.2.0.

\section{RESULTS}

A total of 158 patients (98 men and 60 women) fulfilled the inclusion criteria and agreed to participate (figure 3). Characteristics of these patients are described in table 1 .

Mean AHI was $13.6 \pm 16.1 / \mathrm{h}$. AHI was $<5 / \mathrm{h}$ (no SDB) in 65 $(41 \%)$ of the patients (controls), 43 (27\%) had mild (AHI 5-15/h), $30(19 \%)$ had moderate (AHI 15-30) and $21(13 \%)$ had severe SDB (AHI $>30 / h)$. Overall, subjects with an AHI $\geq 5$ / $\mathrm{h}$ were older ( $\Delta 11.3$ years), and had a higher body mass index (BMI, $\Delta+2.3 \mathrm{~kg} / \mathrm{m}^{2}$ ).

Main postural parameters are described in table 2 . In patients with SDB (AHI $\geq 5 / h$ ) compared with non-SDB patients (AHI $<5 / \mathrm{h})$, we observed higher LFS $(+21 \%, \mathrm{p}<0.001)$, greater $\mathrm{XY}$

Table 1 Anthropometric and sleep characteristics of the total population $(n=158)$ and in no-SDB group $(n=94)$ and SDB group ( $n=64)$

\begin{tabular}{|c|c|c|c|}
\hline & Total & No SDB (AHI <5/h) & SDB $(A H I>5 / h)$ \\
\hline Age mean $\pm S D$ & $45.4 \pm 5.5$ & $38.8 \pm 14.6$ & $50.1 \pm 14.3$ \\
\hline $\mathrm{BMI}$ mean $\pm \mathrm{SD}$ & $27.5 \pm 5.6$ & $26.2 \pm 6.7$ & $28.5 \pm 4.5$ \\
\hline (n) \% women & (158) 38.1 & (94) 38.3 & (64) 37.5 \\
\hline Epworth score mean \pm SD & $8.3 \pm 5.8$ & $7.5 \pm 6.0$ & $8.9 \pm 5.6$ \\
\hline \multicolumn{4}{|l|}{ Comorbidities } \\
\hline Diabetes (\%) & 3.8 & 0.0 & 9.4 \\
\hline Arterial hypertension (\%) & 17.1 & 4.3 & 35.9 \\
\hline Tobacco (\%) & 8.9 & 5.3 & 14.1 \\
\hline Cardiovascular diseases (\%) & 12.7 & 5.3 & 23.4 \\
\hline Hypercholesterolaemia (\%) & 11.4 & 2.1 & 25.0 \\
\hline \multicolumn{4}{|l|}{ Sleep parameters } \\
\hline $\mathrm{AHI}$ mean $\pm \mathrm{SD}$ (median) & $13.6 \pm 16.1(7.8)$ & $2.1 \pm 1.5(1.7)$ & $21.4 \pm 16.9(15.8)$ \\
\hline $\mathrm{ODI}$ mean $\pm \mathrm{SD}$ (median) & $14.3 \pm 16.8(7.8)$ & $3.00 \pm 2.55(2.3)$ & $21.91 \pm 18.05(17.1)$ \\
\hline Mean $\mathrm{SpO}_{2}$ mean $\pm \mathrm{SD}$ & $94.2 \pm 2.0$ & $95.16 \pm 1.58$ & $93.45 \pm 1.87$ \\
\hline $\mathrm{SpO}_{2}<90 \%$ mean $\pm \mathrm{SD}$ & $87.0 \pm 5.5$ & $90.44 \pm 2.91$ & $84.62 \pm 5.59$ \\
\hline
\end{tabular}

$\mathrm{AHI}$, apnoea-hypopnoea index; $\mathrm{BMI}$, body mass index; $\min \mathrm{SpO}_{2}, \%$ of the night spent with and $\mathrm{SpO}_{2}<90 \%$; ODI, oxygen desaturation index; $\mathrm{SDB}$, sleep disorder breathing. 
Table 2 Postural stability characteristics of the total population $(n=158)$ and in no-SDB group $(n=94)$ and SDB group $(n=64)$

\begin{tabular}{lcccc}
\hline & Total & $\begin{array}{l}\text { No SDB } \\
(\text { AHI }<5 / h)\end{array}$ & $\begin{array}{l}\text { SDB } \\
(\text { AHI }>5 / h)\end{array}$ & p Value \\
\hline $\begin{array}{l}\text { Postural parameters } \\
\text { LFS mean } \pm \text { SD }\end{array}$ & $1.12 \pm 0.3$ & $0.99 \pm 0.26$ & $1.21 \pm 0.34$ & $<0.001$ \\
Length XY mean \pm SD & $558.8 \pm 192.8$ & $490.1 \pm 135.5$ & $605.5 \pm 211.8$ & $<0.001$ \\
Mean speed mean \pm SD & $10.9 \pm 3.8$ & $9.6 \pm 2.7$ & $11.8 \pm 4.1$ & $<0.001$ \\
\hline
\end{tabular}

LFS: length of the CoP displacement as a function of the surface of CoP trajectory; length $\mathrm{XY}$ : total displacement of $C O P$ in anteroposterior ( $Y$ axis) and mediolateral $(\mathrm{X}$ axis) plan (length in $\mathrm{mm}$ ); mean speed: mean speed of COP displacement $(\mathrm{mm} / \mathrm{s})$. AHI, apnoea-hypopnoea index; CoP, centre of pressure; SDB, sleep-disordered breathing.

length $(+23 \%, \mathrm{p}<0.001)$ and a higher mean speed $(+23 \%$, $\mathrm{p}<0.001)$. The same was found for $\mathrm{X}$ length alone $(259$ vs $301 \mathrm{~mm}, \mathrm{p}<0.05)$ and for $\mathrm{Y}$ length alone $(357 \mathrm{vs} 459 \mathrm{~mm}$, $\mathrm{p}<0.001)$. There was no significant difference in the stability parameters between men and women in our study (results not shown).

LFS, XY length and mean speed were all significantly correlated with SDB parameters such as the AHI, the ODI, the mean nocturnal $\mathrm{SpO}_{2}$ and the \% of the night spent with and $\mathrm{SpO}_{2}$ $<90 \%$. When the main confounding factors (age, sleepiness and BMI) (table 3) were included in a linear regression model there was still an independent association between AHI, ODI, mean nocturnal $\mathrm{SpO}_{2}$, time with $\mathrm{SpO}_{2}<90$ and LFS, XY length and mean speed. There was also a negative independent association between mean nocturnal $\mathrm{SpO}_{2}$ and the postural stability parameters (figure 4). However, no significant association was found between subjective daytime sleepiness measured by the ESS and postural stability parameters.

Table 3 Association between SDB parameters and postural stability outcomes

\begin{tabular}{|c|c|c|c|}
\hline & Beta coefficient $( \pm 95 \% \mathrm{Cl})$ & $\mathbf{R}_{\text {partial }}$ & $p$ Value \\
\hline \multicolumn{4}{|l|}{ LFS } \\
\hline $\mathrm{AHI}$ & $0.0049(0.001$ to 0.009$)$ & 0.22 & 0.009 \\
\hline ODI 3\% & $0.0043(0.001$ to 0.008$)$ & 0.21 & 0.013 \\
\hline Mean $\mathrm{SpO}_{2}$ & $-0.0578(-0.087$ to -0.029$)$ & -0.32 & $<0.001$ \\
\hline $\mathrm{SpO}_{2}<90$ & 0.0051 (0.001 to 0.009 ) & 0.22 & 0.010 \\
\hline \multicolumn{4}{|l|}{ Mean speed } \\
\hline $\mathrm{AHI}$ & 0.0501 ( 0.010 to 0.089 & 0.25 & 0.014 \\
\hline ODI 3\% & $0.0424(0.006$ to 0.078$)$ & 0.19 & 0.024 \\
\hline Mean $\mathrm{SpO}_{2}$ & $-0.6332(0.016$ to 0.099$)$ & -0.32 & $<0.001$ \\
\hline $\mathrm{SpO}_{2}<90$ & $0.0579(0.016$ to 0.099$)$ & 0.22 & 0.007 \\
\hline \multicolumn{4}{|l|}{$X Y$ length } \\
\hline $\mathrm{AHI}$ & 2.5755 (0.550 to 4.600$)$ & 0.21 & 0.014 \\
\hline ODI $3 \%$ & 2.1822 (0.326 to 4.038$)$ & 0.27 & 0.023 \\
\hline Mean $\mathrm{SpO}_{2}$ & $-32.459(-48.50$ to -16.41$)$ & -0.33 & $<0.001$ \\
\hline $\mathrm{SpO}_{2}<90$ & 2.9677 (0.833 to 5.102$)$ & 0.23 & 0.007 \\
\hline
\end{tabular}

Multiple regression model adjusted for age, BMI and sleepiness (Epworth score) $(n=138)$.

$R_{\text {partial }}$ represents the coefficient of correlation (of the variable with the dependent variable), adjusted for the effect of the other variables in the model.

Length $\mathrm{XY}$ : total displacement of $C O P$ in anteroposterior ( $\mathrm{Y}$ axis) and mediolateral $(\mathrm{X}$ axis) plan (length in $\mathrm{mm}$ ); LFS: length of the COP displacement as a function of the surface of $C O P$ trajectory; mean speed: mean speed of $C O P$ displacement $(\mathrm{mm} / \mathrm{s})$.

$\mathrm{AHI}$, apnoea-hypopnoea index; $\mathrm{BMI}$, body mass index; $\mathrm{COP}$, centre of pressure; ODI, oxygen desaturation index; $\mathrm{SDB}$, sleep-disordered breathing; $\mathrm{SpO}_{2}<90 \%, \%$ of the night spent with and $\mathrm{SpO}_{2}<90 \%$.
A
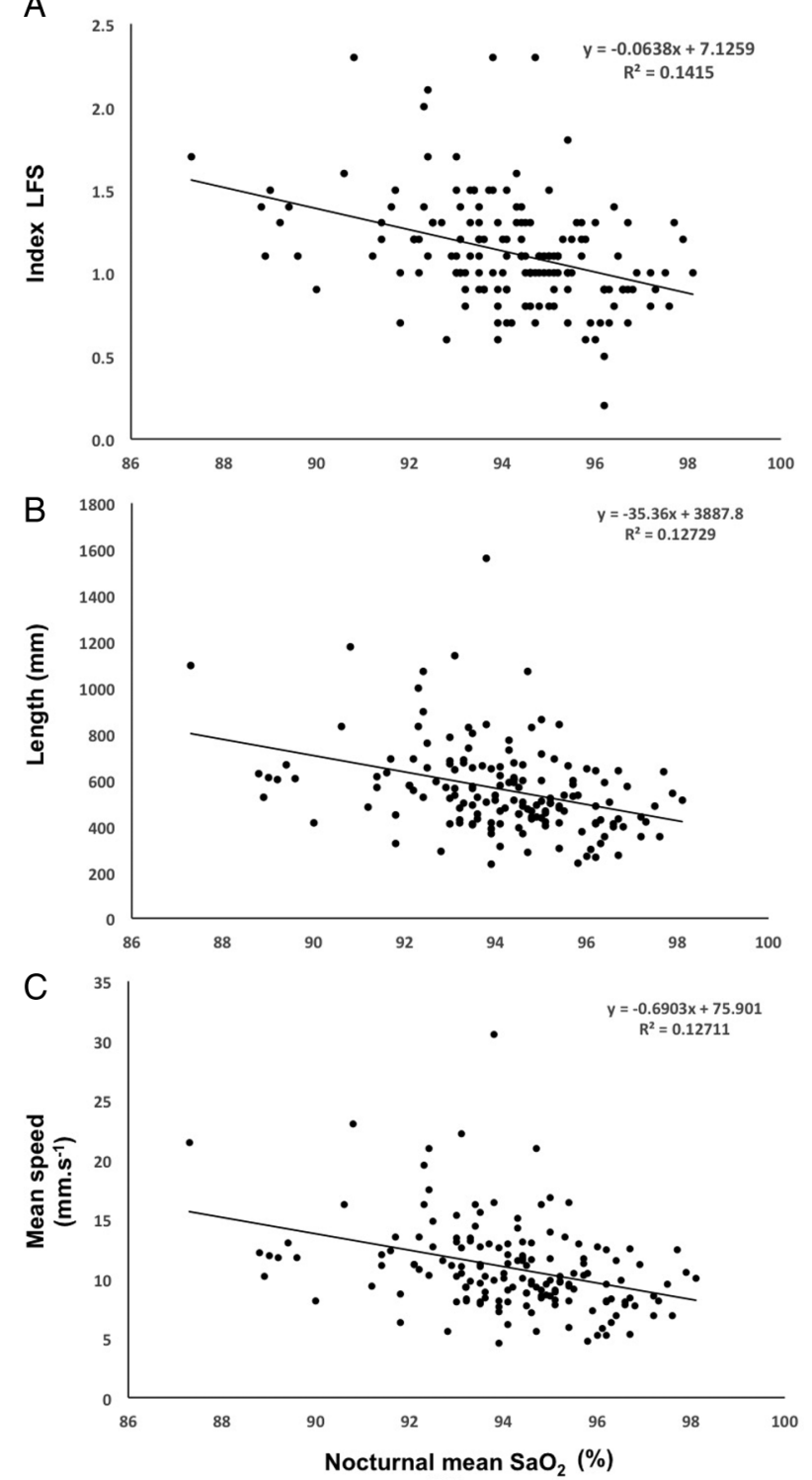

Figure 4 Correlations between nocturnal mean $\mathrm{SpO}_{2}$ and LFS (A) total length $X Y(B)$ and mean speed (C).

We also observed a significant and progressive increase in the main postural instability parameters with increasing SDB severity categories (no $\mathrm{SDB}=\mathrm{AHI}<5 / \mathrm{h}$, mild $=\mathrm{AHI} 5-15 / \mathrm{h}$, moderate AHI $15-30 / \mathrm{h}$ and severe AHI $>30 / \mathrm{h}$ ). Post hoc analysis showed a significant difference in these parameters between no SDB $($ AHI $<5 / \mathrm{h})$ and moderate $(>15 / \mathrm{h})$ and severe $(>30 / \mathrm{h})$ categories $(\mathrm{p}<0.05$ for all). After controlling for age and BMI, there was still a significant increase in LFS, XY length and mean speed with increasing SDB categories (figure 5).

Since diabetes could generate subclinical polyneuropathy influencing postural stability, we compared diabetic and nondiabetic subjects but no significant differences were found in the main stabilometric parameters (LFS: $p=0.77$, mean speed: $\mathrm{p}=0.14$ and $\mathrm{XY}$ length: $\mathrm{p}=0.10$ )

Obesity is also known to affect postural stability. When a subgroup of non-obese subjects (BMI $<30 \mathrm{~kg} / \mathrm{m}^{2}, \mathrm{n}=87$ ) was analysed using a multiple regression model, the same significant association between $\mathrm{AHI}$ and each of the three postural stability outcomes (LFS: $p=0.031$, mean speed: $p=0.013$ and mean XY length: $p=0.013$ ) were found, suggesting that this association was independent from obesity. 


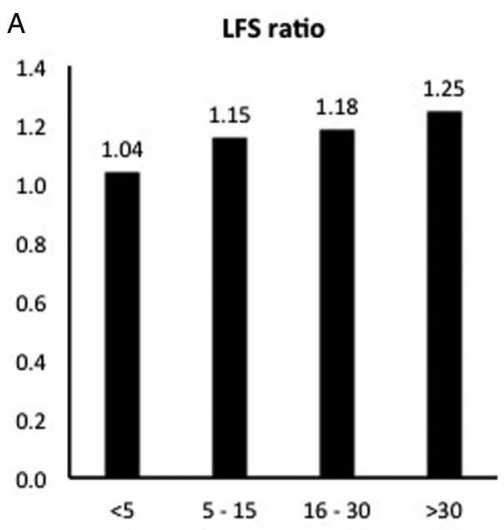

$P$ for trend 0.013
B

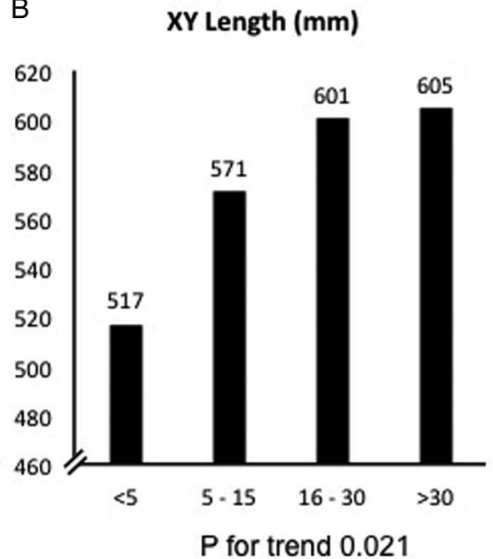

C Mean Speed $\left(\mathbf{m m} \cdot \mathrm{s}^{-1}\right)$

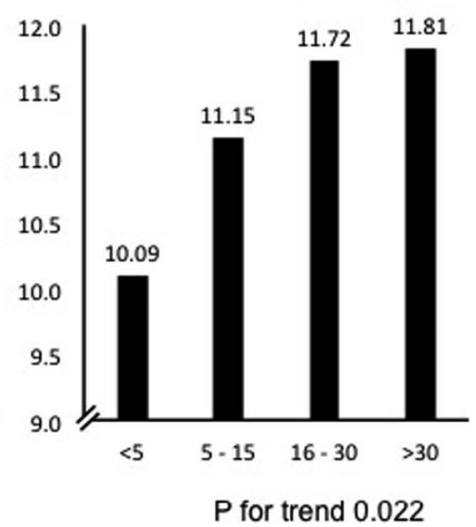

Figure 5 Adjusted means (for age, sleepiness and body mass index) of postural stability parameters according to sleep-disordered breathing (SDB) severity: no SDB apnoea-hypopnoea index <5/h, mild (5-15), moderate (15-30/h) and severe (>30/h).

\section{DISCUSSION}

The main finding of this study is that daytime postural stability seems to be influenced by nocturnal breathing disorders. To our knowledge this is the first study demonstrating an independent association between SDB severity and objectively measured postural impairment. The magnitude of the differences in stability parameters we observed between SDB and non-SDB participants $(+22 \%$ increase in LFS, +25.0 increase in XY length and $+22.9 \%$ increase in mean speed) is even larger than the differences found in Melzer et $a l^{28}$ between elderly fallers and elderly non-fallers: LFS $(+11 \%)$, mean speed $(+10 \%)$ and XY length $(+5 \%)$. We thus believe that SDB-associated postural instability may have a significant clinical impact in the risk of accidental fall and injury. In line with our results, a recent study assessing spatiotemporal gait parameters after 8 weeks of CPAP treatment in patients with SDB found positive associations between SDB and gait quality. ${ }^{29}$ These results tend to confirm that gait control could be affected by SDB-related brain activity deficiencies as suggested by other studies. ${ }^{30} 31$

The factor showing the strongest independent association with the main postural stability parameters was mean nocturnal $\mathrm{SpO}_{2}$. This suggests that nocturnal hypoxaemia in patients with SDB could impair stability control during wakefulness. These results are in line with studies performed at high altitude showing that hypoxaemia could have an impact on postural stability. Wagner et $a l^{32}$ observed impaired standing balance at oxygen levels consistent with altitudes as low as $2438 \mathrm{~m}$. Moreover, postural control is highly dependent on spindle mediated muscle stretch reflexes, which are considered to be crucial for maintaining the upright human stance. ${ }^{33}$ Hypoxia seems to directly alter muscle spindle reactivity, which may thus be one of the mechanism through which hypoxaemia may impair postural stability. This concept is supported by the observation of altered sensorimotor stability occurring in patients suffering from respiratory or circulatory insufficiency. ${ }^{34}$ Moreover, a reduced motor drive to contracting muscle was also noted in human beings during a simulated ascent of Mount Everest ${ }^{35}$ and in patients with hypoxaemia and chronic respiratory insufficiency. ${ }^{36}$ This tends to confirm that hypoxia can alter muscle control and thus postural stability, although the mean oxygen saturation level we observed in SDB is not quite as low as in high altitude or in respiratory insufficiency studies. Other mechanisms could thus be involved.

Considering that SDB disrupts sleep continuity, decreases slow wave sleep and total sleep time, we can also suspect that the effects we observed could be partially mediated by a decrease in sleep quality comparable to a sleep deprivation. A previous study by Fabbri et $a l^{37}$ showed an effect of sleep deprivation on LFS ratio and total length of $\mathrm{CoP}$ suggesting that sleep curtailment can induce a deactivation of brain areas mediating attention and also of the structures responsible for optimal postural stability. Attention has also been shown to be a key factor to maintain stability during daytime. Bougard et $a l^{38}$ previously showed that postural control fluctuates according to a circadian rhythm. The lack of association we found between the ESS score and the stability parameters does not confirm in our sample this association between postural stability and sleepiness. This may be explained by the subjective aspect of the ESS, which can be influenced by different factors such as depression, for example, and was shown to be poorly correlated with objectively measured sleepiness. ${ }^{39}$

These results should stimulate further research on stabilometry in patients with SDB in order to assess if SDB-associated postural instability is reversible after treatment. The exact mechanism of the association between SDB and postural instability should also be investigated through experimental studies assessing the effects of induced intermittent hypoxia, constant nocturnal hypoxia or induced sleep fragmentation (without hypoxia) on postural stability.

There are limitations in our study that need to be taken into account. First, this study was observational and these results should be confirmed by an interventional study assessing the effect of SDB treatment on postural stability or by a prospective study on a large cohort of subjects with and without SDB. Second, the absence of objective sleep evaluation in our subjects did not allow assessing the effect of sleep quality and duration on postural stability. Third, the relatively small sample did not allow stratification by gender, even if gender is not recognised as significant factor influencing stability ${ }^{40}$ and we did not find significant differences in the stability parameters between men and women in our study. Finally, daytime sleepiness was only assessed subjectively through the ESS. Further studies using objective sleepiness assessments and attention tests are needed to determine the effect of SDB-associated daytime sleepiness on postural stability.

\section{CONCLUSION}

Our results suggest the presence of an independent association between nocturnal breathing disturbances and daytime postural 
stability with a dose-response effect according to SDB severity. We believe that these results should raise awareness among clinicians evaluating patients with SDB that they might suffer from postural instability. Further prospective and interventional studies are needed to confirm this association and assess its reversibility with SDB treatment.

Contributors The conception and design of the study, or acquisition of data or analysis and interpretation of data: FD, YG and SV. Drafting the article or revising it critically for important intellectual content: $F D, J H R, O C$ and $\mathrm{RH}$. Final approval of the version to be submitted: FD, YG, SV, JHR, OC and RH.

Competing interests None declared.

Patient consent Obtained.

Ethics approval Cantonal Ethics Committee of Lausanne, Switzerland (\# 474/12).

Provenance and peer review Not commissioned; externally peer reviewed.

\section{REFERENCES}

1 White DP. Sleep-related breathing disorder. 2. Pathophysiology of obstructive sleep apnoea. Thorax 1995;50:797-804.

2 Peppard PE, Young T, Palta M, et al. Prospective study of the association between sleep-disordered breathing and hypertension. N Engl J Med 2000;342:1378-84.

3 Heinzer R, Vat S, Marques-Vidal P, et al. Prevalence of sleep-disordered breathing in the general population: the HypnoLaus study. Lancet Respir Med 2015;3:310-8.

4 Gottlieb DJ, Yenokyan G, Newman AB, et al. Prospective study of obstructive sleep apnea and incident coronary heart disease and heart failure: the sleep heart health study. Circulation 2010;122:352-60.

5 Yaggi HK, Concato J, Kernan WN, et al. Obstructive sleep apnea as a risk factor for stroke and death. N Engl J Med 2005;353:2034-41.

6 Redline S, Yenokyan G, Gottlieb DJ, et al. Obstructive sleep apnea-hypopnea and incident stroke: the sleep heart health study. Am J Respir Crit Care Med 2010;182:269-77.

7 Marin JM, Carrizo SJ, Vicente E, et al. Long-term cardiovascular outcomes in men with obstructive sleep apnoea-hypopnoea with or without treatment with continuous positive airway pressure: an observational study. Lancet 2005;365:1046-53.

8 Terán-Santos J, Jiménez-Gómez A, Cordero-Guevara J. The association between sleep apnea and the risk of traffic accidents. Cooperative Group Burgos-Santander. N Engl J Med 1999;340:847-51.

9 Peppard PE, Szklo-Coxe M, Hla KM, et al. Longitudinal association of sleep-related breathing disorder and depression. Arch Intern Med 2006;166:1709-15.

10 Kendzerska T, Gershon AS, Hawker G, et al. Obstructive sleep apnea and incident diabetes. A historical cohort study. Am I Respir Crit Care Med 2014;190: 218-25.

11 Mazza S, Pépin JL, Naëgelé B, et al. Driving ability in sleep apnoea patients before and after CPAP treatment: evaluation on a road safety platform. Eur Respir J 2006;28:1020-8.

12 Shumway-Cook A, Woollacott MH. Motor control: Theory and practical applications. 2nd edn. Baltimore, Maryland: Lippincott Williams \& Wilkins, 2001.

13 Nardone A, Tarantola J, Giordano A, et al. Fatigue effects on body balance. Electroencephalogr Clin Neurophysiol 1997;105:309-20.

14 Duarte M, Zatsiorsky VM. Effects of body lean and visual information on the equilibrium maintenance during stance. Exp Brain Res 2002;146:60-9.

15 Collins JJ, De Luca CJ. Open-loop and closed-loop control of posture: a random-walk analysis of center-of-pressure trajectories. Exp Brain Res 1993;95:308-18.
16 Black SE, Maki BE, GR F. Aging, imbalance and falls. In: Sharps JA, Barber HO, eds. The vestibulo-ocular reflex and vertigo. New York: Raven Press, 1993:317-35.

17 Avni N, Avni I, Barenboim E, et al. Brief posturographic test as an indicator of fatigue. Psychiatry Clin Neurosci 2006;60:340-6.

18 Gribble PA, Hertel J. Changes in postural control during a 48-hr. sleep deprivation period. Percept Mot Skills 2004;99(Pt 1):1035-45.

19 Liu Y, Higuchi S, Motohashi Y. Changes in postural sway during a period of sustained wakefulness in male adults. Occup Med (Lond) 2001;51:490-5.

20 Nakano T, Araki K, Michimori A, et al. Nineteen-hour variation of postural sway, alertness and rectal temperature during sleep deprivation. Psychiatry Clin Neurosci 2001:55:277-8.

21 Drummond SP, Brown GG, Stricker JL, et al. Sleep deprivation-induced reduction in cortical functional response to serial subtraction. Neuroreport 1999;10: 3745-8.

22 Thomas M, Sing H, Belenky G, et al. Neural basis of alertness and cognitive performance impairments during sleepiness. I. Effects of $24 \mathrm{~h}$ of sleep deprivation on waking human regional brain activity. J Sleep Res 2000;9:335-52.

23 Degache $F$, Larghi $G$, Faiss $R$, et al. Hypobaric versus normobaric hypoxia: same effects on postural stability? High Alt Med Biol 2012;13:40-5.

24 Holness $D E$, Fraser WD, Eastman DE, et al. Postural stability during slow-onset and rapid-onset hypoxia. Aviat Space Environ Med 1982;53:647-51.

25 Wuehr M, Pradhan C, Novozhilov S, et al. Inadequate interaction between openand closed-loop postural control in phobic postural vertigo. I Neurol 2013;260:1314-23.

26 Gagey G, Weber B. Posturologie, régulation et dérèglement de la station debout. Paris: Masson, 1999

27 Johns MW. A new method for measuring daytime sleepiness: the Epworth sleepiness scale. Sleep 1991;14:540-5.

28 Melzer I, Benjuya N, Kaplanski J. Postural stability in the elderly: a comparison between fallers and non-fallers. Age Ageing 2004;33:602-7.

29 Celle S, Annweiler C, Camicioli R, et al. Sleep-related breathing disorders and gait variability: a cross-sectional preliminary study. BMC Pulm Med 2014;14:140.

30 Beauchet $\mathrm{O}$, Allali G, Launay C, et al. Gait variability at fast-pace walking speed: a biomarker of mild cognitive impairment? J Nutr Health Aging 2013;17:235-9.

31 Beauchet $\mathrm{O}$, Annweiler $\mathrm{C}$, Celle $\mathrm{S}$, et al. Higher gait variability is associated with decreased parietal gray matter volume among healthy older adults. Brain Topogr 2014;27:293-5.

32 Wagner $L S$, Oakley SR, Vang $P$, et al. Hypoxia-induced changes in standing balance. Aviat Space Envir Med 2011;82:518-22.

33 Loram ID, Maganaris CN, Lakie M. Paradoxical muscle movement during postural control. Med Sci Sports Exerc 2009;41:198-204.

34 Delliaux S, Jammes Y. Effects of hypoxia on muscle response to tendon vibration in humans. Muscle Nerve 2006;34:754-61.

35 Caquelard F, Burnet H, Tagliarini F, et al. Effects of prolonged hypobaric hypoxia on human skeletal muscle function and electromyographic events. Clin Sci 2000;98:329-37.

36 Zattara-Hartmann MC, Badier M, Guillot C, et al. Maximal force and endurance to fatigue of respiratory and skeletal muscles in chronic hypoxemic patients: the effects of oxygen breathing. Muscle Nerve 1995;18:495-502.

37 Fabbri M, Martoni M, Esposito MJ, et al. Postural control after a night without sleep. Neuropsychologia 2006;44:2520-5.

38 Bougard C, Lepelley MC, Davenne D. The influences of time-of-day and sleep deprivation on postural control. Exp Brain Res 2011;209:109-15.

39 Chervin RD, Aldrich MS. The Epworth Sleepiness Scale May not reflect objective measures of sleepiness or sleep apnea. Neurology 1999;52:125-31.

40 Melam G, Buragadda S, Alhusaini A, et al. Gender differences in static and dynamic postural stability parameters in community dwelling healthy older adults. Middle East J Sci Res 2014;22:1259-64. 